\title{
Evaluation of the Behavior in Water of a Biomaterial Composed of Different Phases of Calcium Phosphate
}

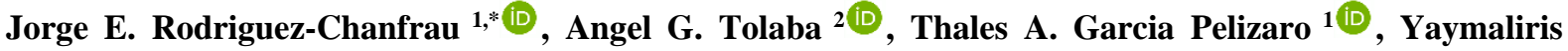 \\ Veranes-Pantoja $^{3}$ (iD), Antonio C. Guastaldi ${ }^{1}$ (D) \\ 1 Group of Biomaterials, Department of Physical Chemistry, Institute of Chemistry, Sao Paulo State University (UNESP), \\ Araraquara, SP, 14800-060, Brazil \\ 2 Mathematics Department, Science Faculty, National University of Salta, CP A4400, Salta, Argentina \\ 3 Center of Biomaterials, University of Havana. Vedado, La Habana, Cuba \\ * Correspondence: jerodriguez354@gmail.com;
}

Scopus Author ID 7801488065

Received: 19.07.2020; Revised: 9.08.2020; Accepted: 12.08.2020; Published: 15.08.2020

\begin{abstract}
The synthesis of calcium phosphates of biological interest has been one of the strategies studied in the field of tissue regeneration due to its similarity to the inorganic components of bone. One of the aspects studied has been the process of dissolution of calcium phosphates in water and physiological serum, with the aim of being able to know everything related to the behavior of these materials during the bone regeneration process. The objective of this work was to evaluate the behavior in the water of a biomaterial composed of a three-phase mixture of calcium phosphate for use in tissue regeneration. Three phases of calcium phosphate were synthesized. A biomaterial with a mixture of these phases was elaborated and placed in water at $37^{\circ} \mathrm{C}$. The amount of calcium and phosphorus released was determined over time. The treated samples were evaluated by X-ray diffractometry and infrared spectrometry. The results of this study demonstrated that for calcium, the release overtime was not significant due to the reaction of these ions in solution with phosphate ions and the subsequent precipitation in the studied material. While for phosphorus, the release over time was significant. The results corroborate that the use of a triphasic mixture of calcium phosphates allows us to produce a biomaterial suitable for use as a material in tissue regeneration.
\end{abstract}

Keywords: Biomaterials; Calcium phosphate; Release study.

(C) 2020 by the authors. This article is an open-access article distributed under the terms and conditions of the Creative Commons Attribution (CC BY) license (https://creativecommons.org/licenses/by/4.0/).

\section{Introduction}

Bone is a structure formed by an inorganic part that contains calcium phosphates, mainly in the form of hydroxyapatite and an organic phase composed of collagen, proteins, and amino acids [1]. The bone tissue is metabolically active, consisting of an extracellular matrix and osteoclast cells, osteoblast, and osteocytes. These cells are in charge of maintaining and regenerating bone, providing it with the necessary strength and toughness [1, 2]. However, despite the properties of bone to regenerate without scar formation, this process depends on the type and magnitude of the defect, which leads to the search for new strategies that allow improving and increasing the capacity for regeneration.

The synthesis of calcium phosphates of biological interest, such as amorphous calcium phosphate (ACP), calcium triphosphate (TCP), octacalcium phosphate (OCP) and hydroxyapatite (HA) has been one of the strategies that in recent years has been studied within the field of tissue regeneration, especially bone regeneration. These phosphates have a 
biological and medical interest due to their biocompatibility, bioactivity, resorbability, and chemical structure that makes them similar to the inorganic components of bone, making it a suitable material to be used in bone regeneration processes [1, 3-7].

One of the aspects studied has been the process of dissolution of calcium phosphates of biological interest in water and physiological serum, with the aim of being able to know everything related to the behavior of these materials during the bone regeneration process. Factors such as the synthesis method, the content of different phases in the material, the density, the ionic substitutions in the apatite lattice, and the microstructure of the material, make the dissolution behavior vary widely in calcium phosphates [8-11].

The objective of this work was to evaluate the behavior in the water of a biomaterial composed of a three-phase mixture of calcium phosphate for use in tissue regeneration.

\section{Materials and Methods}

\subsection{Synthesis of calcium phosphate and preparation of tablets.}

Amorphous calcium phosphate (ACP), tricalcium phosphate (TCP), and octacalcium phosphate (OCP) were synthesized according to Debone Piazza et al. [3]. Tablets (300 mg by weight) with the mixture of the three phosphate phases previously synthesized (100 $\mathrm{mg}$ in each phase) were prepared, according to Rodriguez Chanfrau [7].

\subsection{Release study.}

Pre-weighed tablets (initial weight) were placed in a $10 \mathrm{~mL}$ capacity beaker. $5 \mathrm{~mL}$ of distilled water was added and placed in an air recirculation oven at $37^{\circ} \mathrm{C}$. Times of $12,24,48$, and 72 hours were evaluated. At the end of each time, the samples were removed from the beaker and placed on filter paper to remove drops of water left on the surface. The tablets were weighed (wet weight), and the amount of water absorbed was determined. Subsequently, each dried tablet was crushed, and the powder obtained used in the different analyzes and characterizations. In parallel, tablets were used as control (zero time). The experiments were performed in triplicates.

\subsection{Determination of calcium concentration.}

Calcium was determined by atomic absorption spectroscopy with a Spectr AA-50 spectrophotometer (VARIAN, USA) using an acetylene flame in the air and the $422.7 \mathrm{~nm}$ wavelength line according to Garcia Pellizaro et al. [5].

\subsection{Determination of phosphorus concentration.}

The percentage of phosphorus is determined by spectrophotometric measurement of the blue color of the phosphomolybdic complex that is formed by treating the samples with the molybdate-tartrate mixture, according to PNO procedure 01.047 of the Biomaterials Center, Havana, Cuba. With the values of calcium and phosphors, the $\mathrm{Ca} / \mathrm{P}$ ratio was determined.

\subsection{X-ray powder diffraction studies.}

The XRD spectra were recorded at room temperature $\left(25^{\circ} \mathrm{C}\right)$ with a SIEMENS 5000, DIFFRAC PLUS XRD diffractometer (Germany) with BRAGG-Brentano geometry, $\mathrm{Cu} \mathrm{K} \alpha$ radiation $(\lambda=0.154 \mathrm{~nm})$, Flicker detector and graphite monochromator. A scattering angle range 
from $4^{\circ}$ to $80^{\circ}$ with a $2 \theta$ step interval of $0.02^{\circ}$ was used. The samples were placed in the glass sample holder, analyzed under plateau conditions. An operating voltage of $40 \mathrm{kV}$ and a current of $30 \mathrm{~mA}$ was utilized, and the intensities were measured in the range of $5^{\circ}<2 \theta<30^{\circ}$. Peak separations were carried out using Gaussian deconvolution. The d-spacings were calculated using the Bragg equation. Crystallographic search match software was used to identify the crystal structure of samples.

The crystallinity index for each of the samples was calculated according to the method defined by Person et al. [13]. For this semi-quantitative analysis method, the reflections (2 0 2), (3 000$),\left(\begin{array}{lll}2 & 1 & 1\end{array}\right)$ and ( $\left.\begin{array}{lll}1 & 1 & 2\end{array}\right)$, appearing between the $2 \Theta$ values of $30^{\circ}$ and $35^{\circ}$, were used.

\subsection{FTIR spectroscopy.}

FTIR spectra of the samples were measured on an FTIR-VERTEX 70/BRUKER spectrometer (Germany). Transmission mode was used with 64 cumulative scans and a resolution of $4 \mathrm{~cm}^{-1}$, in the frequency range of 4000 to $400 \mathrm{~cm}^{-1}$.

\subsection{Statistical evaluation.}

Statistical evaluation was performed using a one-way ANOVA. The different times were taken as factors, and as variable responses were the percentage of calcium and phosphorus, as well as the $\mathrm{Ca} / \mathrm{P}$ ratio. Previously it was verifying the assumptions that guarantee a correct interpretation of the design by evaluating normality (Shapiro Wills test), homoscedasticity (Levene's test), and independence through the scatter plot. In all cases, the significance of $\alpha=5 \%$ was used. All data were processed using the statistical software InfoStat (2017 version).

\section{Results and Discussion}

$\mathrm{Ca} / \mathrm{P}$ molar ratio of each of the calcium phosphate phases used for the preparation of the tablets was $1.49,1.51$, and 1.31 for ACP, TCP, and OCP, respectively. These results coincide with the range of values reported by other authors for each phase of calcium phosphate studied in this work [14-21]. Tablets with a diameter of $13.0 \pm 0.1 \mathrm{~mm}$, a height of $2.5 \pm 0.2$ $\mathrm{mm}$, and a weight of $257.7 \pm 0.015 \mathrm{mg}$ were obtained.

Table 1 shows the remaining content of calcium and phosphorus in the tablets after treatment over time, as well as the $\mathrm{Ca} / \mathrm{P}$ ratio for each of the times studied. Meanwhile, Table 2 shows the percentage of calcium and phosphorus released over time.

The results showed that in the time studied, only $1.5 \%$ calcium is released. However, in the case of the phosphorus release study, it was observed that at 72 hours, about $26.2 \%$ had been released (Table 2). The statistical analysis showed that the data evaluated complies with the parameters of normality $(\mathrm{p}=0.5618$ and $\mathrm{p}=0.2729$ for calcium and phosphorus, respectively) and homoscedasticity $(\mathrm{p}=0.3810$ and $\mathrm{p}=0.1220$ for calcium and phosphorus, respectively). The results of the analysis by means of the scatter plot showed that for both cases, the data presented independence. Based on these results, a parametric ANOVA was applied, verifying that in the case of the calcium analysis there were no significant differences between the data over time ( $p=0.9911)$, while, in the case of the phosphorus, a significant difference in time was observed $(\mathrm{p}=0.0001)$. 
Table 1. Content of calcium and phosphorus in the tablets after treatment over time and $\mathrm{Ca} / \mathrm{P}$ ration

(Media/SD).

\begin{tabular}{l|c|c|c|c} 
Time (h) & Weigth Tablet $(\mathbf{g})$ & Ca $(\mathbf{m g})$ & $\mathbf{P}(\mathbf{m g})$ & Ca/P ration \\
\hline $\mathbf{0}$ & $0.2324 / 0.009$ & $61.9 / 1.9$ & $59.9 / 2.0$ & 1.03 \\
\hline $\mathbf{1 2}$ & $0.2305 / 0.002$ & $61.7 / 1.4$ & $56.6 / 2.6$ & 1.09 \\
\hline $\mathbf{2 4}$ & $0.2291 / 0.003$ & $61.8 / 2.2$ & $53.7 / 0.6$ & 1.15 \\
\hline $\mathbf{4 8}$ & $0.2166 / 0.001$ & $61.1 / 1.5$ & $49.7 / 0.7$ & 1.23 \\
\hline $\mathbf{7 2}$ & $0.2456 / 0.007$ & $61.0 / 1.4$ & $44.2 / 2.4$ & 1.38
\end{tabular}

Table 2. Percentage of calcium and phosphorus released over time.

\begin{tabular}{l|l|l|l|l} 
Time (h) & Ca (mg) & $\mathbf{\%}$ & $\mathbf{P}(\mathbf{m g})$ & $\mathbf{\%}$ \\
\hline $\mathbf{0}$ & 0 & 0 & 0 & 0 \\
\hline $\mathbf{1 2}$ & 0.2 & 0.3 & 3.3 & 5.5 \\
\hline $\mathbf{2 4}$ & 0.1 & 0.2 & 6,2 & 10.4 \\
\hline $\mathbf{4 8}$ & 0.8 & 1.3 & 10.2 & 17.0 \\
\hline $\mathbf{7 2}$ & 0.9 & 1.5 & 15.7 & 26.2
\end{tabular}

In this study, a biomaterial consisting of a three-phase mixture of calcium phosphates (ACP, OCP, and TCP/HA) was used. One of the most important properties of calcium phosphates is the possibility of predicting their possible behavior in vivo and their solubility in water, demonstrating that at physiological $\mathrm{pH}$, the solubility varies depending on their chemical structure and the $\mathrm{Ca} / \mathrm{P}$ ratio. A higher value of the $\mathrm{Ca} / \mathrm{P}$ ratio implies a lower solubility. Of the phosphates of biological interest, HA is the most insoluble phase. [20]. Therefore, following this reasoning, it could be predicted that in the case of the biomaterial studied, the solubility in water could be OCP greater than ACP, greater than TCP/HA.

Studies reported in the literature showed that during the calcium phosphate dissolution process, a precipitation mechanism competes in parallel. A placed the calcium phosphates in water, phosphate ions dissolve more readily than calcium ions. In this process, the calcium ions react with the $\mathrm{HPO}_{4}{ }^{-2}$ ions, forming calcium phosphate, which precipitates on the surface of the material. This mechanism is simultaneously favored by the presence of HA in the sample $[11,22-23]$. Both processes occur in parallel, being favored by the exposure time, temperature, and agitation of the medium. The results obtained in this work show that over time the release of phosphorus over time increases significantly, while the calcium concentration is not significant, which could be caused by the possible precipitation mechanism and the low concentration of this ion in the samples.

An increase in time is observed in the case of the $\mathrm{Ca} / \mathrm{P}$ ratio (Table 1). The statistical analysis showed that the data complies with the normality $(\mathrm{p}=0.5339)$ and homoscedasticity ( $\mathrm{p}=0.3460)$; as well as with the independence, so it was evaluated by means of a parametric ANOVA. The results showed that there were significant differences over time $(p=0.0101)$.

A possible explanation may be given to the dissolution process itself, where a quantity of phosphate ions is released into the medium. On the other hand, it is known that the OCP phase and the ACP phase are HA precursors. The OCP phase is transformed into more stable $\mathrm{HA}$ by means of a hydrolysis process that occurs at a $\mathrm{pH}$ between 6.2 and 7.4, and a temperature that ranges between $25^{\circ} \mathrm{C}$ and $37^{\circ} \mathrm{C}$. Higher temperatures or $\mathrm{pH}$ facilitate the formation of biological apatites. This process is apparently controlled by transportation and nucleation mechanisms, and they influence the $\mathrm{Ca} / \mathrm{P}$ ratio and the degree of saturation. While in the case of the ACP phase, its conversion to HA can be done directly or its conversion to an intermediate phase OCP and calcium deficient HA. In both cases, neutral or alkaline $\mathrm{pHs}$ favor the process and act on the $\mathrm{Ca} / \mathrm{P}$ ratio $[11,20]$. 
Table 3 shows the results of water absorption and weight percentage over time. An increase in the weight of the tablets of approximately $51 \%$, due to the absorption of water, was observed.

Table 3. Water absorption over time (mean / SD).

\begin{tabular}{l|c|c} 
Time (h) & Water absorption $(\mathbf{m g})$ & \% in weigh \\
\hline $\mathbf{0}$ & 0 & 0 \\
\hline $\mathbf{1 2}$ & $89.0 / 5.4$ & 33.7 \\
\hline $\mathbf{2 4}$ & $95.3 / 6.3$ & 35.8 \\
\hline $\mathbf{4 8}$ & $122.9 / 4.5$ & 48.8 \\
\hline $\mathbf{7 2}$ & $145.2 / 8.4$ & 51.6
\end{tabular}

Figure 1 shows the X-ray diffractograms of the tablets treated at different times. No major changes were observed in the diffractograms, except that the intensity of the signals between $25^{\circ}$ and $40^{\circ} 2 \theta$ increase over time. This area corresponds mainly to the presence of $\mathrm{HA}, \mathrm{ACP}$, and $\mathrm{CaO}$ (Figure 2). Specifically, an increase in the time of the peak to $26.4^{\mathrm{o}} 2 \theta$, which corresponds to the presence of calcium-deficient HA, and the peak to $35^{\circ} 2 \theta$, that corresponds to the presence of $\mathrm{CaO}$, were observed. On the other hand, signals between $10^{\circ}$ and $15^{\circ} 2 \theta$ tend to decrease slightly over time.

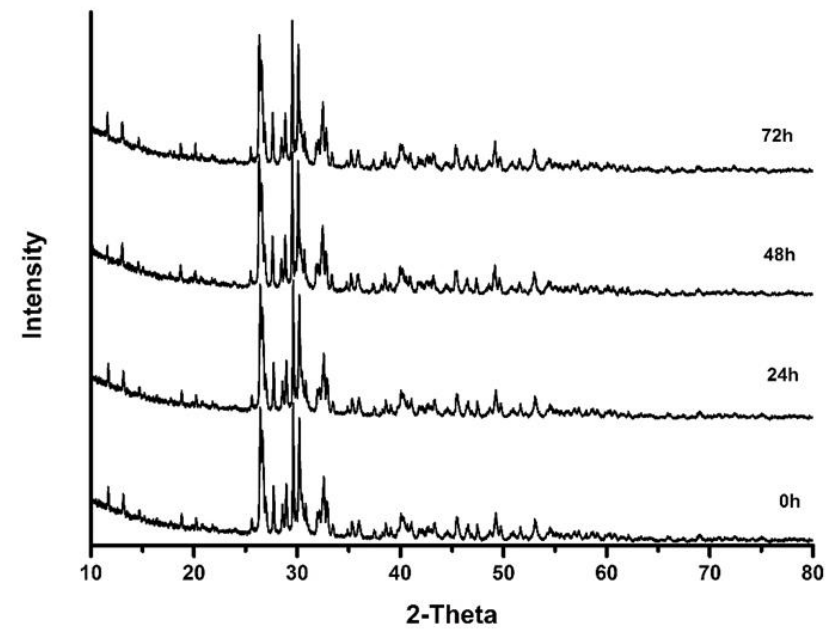

Figure 1. X-ray diffractograms of the tablets treated at different times.

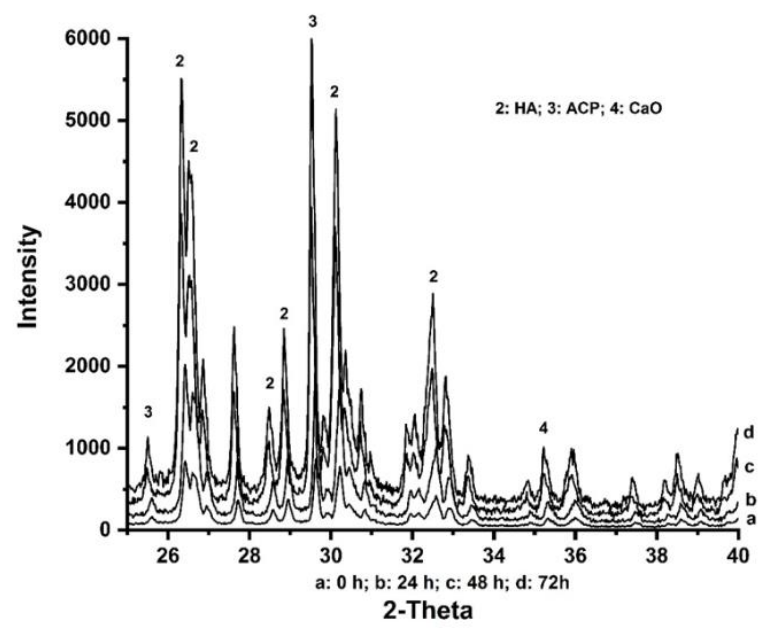

Figure 2. X-ray diffractograms of the tablets treated at different times (range between $25^{\circ}$ and $40^{\circ} 2 \theta$ ). 
The determination of the crystallinity index according to the methodology proposed by Parsoon showed that no appreciable variations of this index occurred over time $(1.11 ; 1.10$; 1.12 and 1.11 for time zero, 24,48 , and 72 hours, respectively).

Figure 3 shows the FTIR spectra of the samples treated at different times. Typical bands of the presence of phosphates in the samples are observed in all cases $\left(1207 \mathrm{~cm}^{-1}, 1186 \mathrm{~cm}^{-1}\right.$, $1136 \mathrm{~cm}^{-1}, 1064 \mathrm{~cm}^{-1}$, and $1068 \mathrm{~cm}^{-1}$ ). No appreciable changes were observed in the spectra of the samples over time, except in the band at $725 \mathrm{~cm}^{-1}$, which suffered a slight increase over time. This band corresponds to the presence of carbonate in the sample.

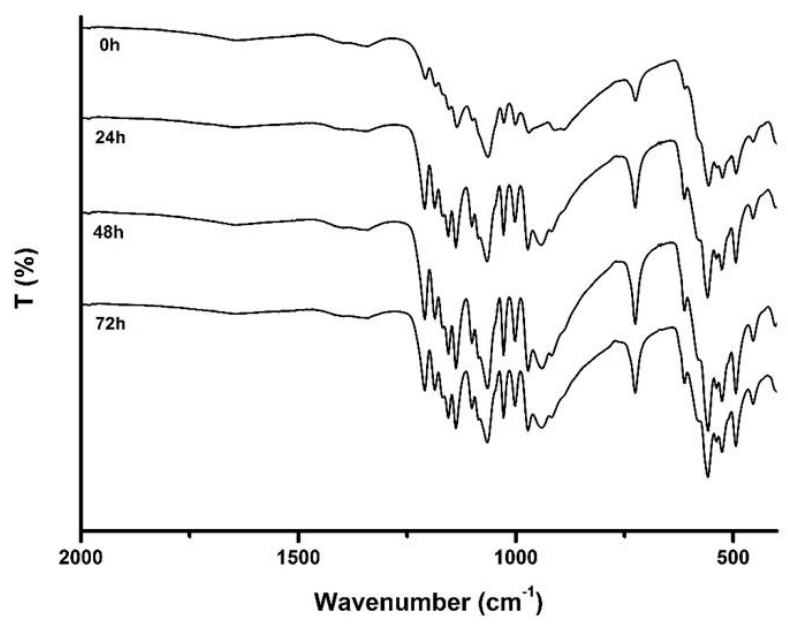

Figure 3. FTIR spectra of the samples treated at different times.

It has been reported in the literature that during the bone regeneration process, HA binds to bone through a layer of apatite that develops on the surface of the material. This layer is formed from the precipitation of calcium phosphate formed during the solubility process of the material in the medium. The apatite layer that forms on the HA surface is generally calcium deficient, with a $\mathrm{Ca} / \mathrm{P}$ ratio ranging from 1.25 to 1.66. It also shows that the formation of carbonates in the material. [11]. This study shows that calcium-deficient HA formation and the presence of carbonate occurred during the process of exposing the biomaterial in water.

\section{Conclusions}

The results of this study demonstrated the release of phosphate ions is significant over time, while the release of calcium ions overtime was not significant. This is our opinion, was motivated by the fact that during the process, the released calcium ions react phosphate ions with the consequent formation of apatite and subsequent precipitation on the studied material. The results suggest that during the study, the OCP and ACP phases undergo a hydrolysis process with the consequent formation of calcium-deficient hydroxyapatite and the formation of calcium carbonate. Furthermore, it is verified that over time the $\mathrm{Ca} / \mathrm{P}$ ratio increases significantly due to the structural variations that the material undergoes.

The results corroborate that the use of a triphasic mixture of calcium phosphates allows us to produce a biomaterial suitable for use as a material in tissue regeneration.

\section{Funding}

This research was funded by the Coordination for the Improvement of Higher Education Personnel (CAPES) (CAPES-MES project 186/13). 


\section{Acknowledgments}

The authors thank X-ray laboratory and the Scanning Electron Microscopy Laboratory of the Institute of Chemistry, UNESP. Araraquara, Brazil, for the measurements made.

\section{Conflicts of Interest}

The authors declare no conflict of interest.

\section{References}

1. Gomes, D.S.; Santos, A.M.C.; Neves, G.A.; Menezes, R.R. A brief review on hydroxyapatite production and use in biomedicine. Cerâmica [online] 2019, 65, 282-302, https://doi.org/10.1590/036669132019653742706.

2. Lotinun, S.; Kiviranta, R.; Matsubara, T.; Alzate, J. A.; Neff, L.; Lüth, A.; Koskivirta, I.; Kleuser, B.; Vacher, J.; Vuorio, E.; Horne, W. C.; Baron, R. Osteoclast-specific cathepsin K deletion stimulates S1P-dependent bone formation. J Clin Invest. 2013, 123, 666-681, https://doi.org/10.1172/JCI64840.

3. Piazza, R.D.; Pelizaro, T.A.G.; Rodriguez-Chanfrau, J.E.; La Serna, A.A.; Veranes-Pantoja, Y.; Guastaldi, A.C. Calcium phosphates nanoparticles: The effect of freeze-drying on particle size reduction. Materials Chemistry and Physics 2020, 239, https://doi.org/10.1016/j.matchemphys.2019.122004.

4. Rodriguez-Chanfrau, J.E.; Garcia Pelizaro, T.A.; da Silva, R.M.; Tolaba, A.G.; Pizoni, E.; Veranes-Pantoja, Y.; Guastaldi, A.C. Synthesis by wet chemical method of different phases of apatites applying ultrasound. Journal of Bionanoscience 2018, 12, 134-141, https://doi.org/10.1166/jbns.2018.1502.

5. Garcia Pelizaro, T.A.; Tolaba, A.G.; Rodriguez-Chanfrau, J.E.; Veranes-Pantoja, Y.; Guastaldi, A.C. Influence of the application of ultrasound during the synthesis of calcium phosphates. Journal of Bionanoscience 2018, 12, 733-738, https://doi.org/10.1166/jbns.2018.1585.

6. Tolaba, A.G.; Pellizaro, T.A.G.; Rodriguez-Chanfrau, J.E.; Guastaldi, A.C. Statistical evaluation of the effect of ultrasound on the synthesis of calcium phosphates. Biointerface Research in Applied Chemistry 2019, 9, 4343-4348, https://doi.org/10.33263/BRIAC95345348.

7. Rodriguez-Chanfrau, J.E. Evaluation of the influence of microwaves radiation on a biomaterial composed of three phases of calcium phosphates. Biointerface Research in Applied Chemistry 2020, 10, 5141-5144, https://doi.org/10.33263/BRIAC102.141144.

8. Fulmer, M.T.; Ison, I.C.; Hankermayer, C.R.; Constantz, B.R.; Ross, J. Measurements of the solubilities and dissolution rates ofseveral hydroxyapatite. Biomaterials 2002, 23, 751-755, https://doi.org/10.1016/s01429612(01)00180-6.

9. Fazan, F.; Marquis, P.M. Dissolution behavior of plasma-sprayed hydroxyapatite coatings. J. Mater. Sci.: Mater. Med. 2000, 11, 782-792, https://doi.org/10.1023/a:1008901512273.

10. Ducheyne, P.; Radin, S.; King, L. The effect of calcium phosphate ceramic composition and structure on in vitro behavior: I. Dissolution. J. Biomed. Mater. Res. 1993, 27, 25-34, https://doi.org/10.1002/jbm.820270105.

11. Yang, H.Y.; Thompson, I.; Yang, S.F.; Chi, X.P.; Evans, J.R.; Cook, R.J. Dissolution characteristics of extrusion freeformed hydroxyapatite-tricalcium phosphate scaffolds. J Mater Sci Mater Med. 2008, 19, 3345-3353, https://doi.org/10.1007/s10856-008-3473-7.

12. Wang, L.; Nancollas, G.H. Calcium orthophosphates: crystallization and dissolution. Chem Rev. 2008, 108, 4628-4669, https://doi.org/10.1021/cr0782574.

13. Person, A.; Bocherens, H.; Saliege, J.F.; Paris, F.; Zeitoun, V.; Gerard, M. Early diagenetic evolution of bone phosphate: an X-ray diffractometry analysis. Journal of Archaeological Science 1995, 22, 211-221, https://doi.org/10.1006/jasc.1995.0023.

14. Jeong, J.; Kim, J.H.; Shim, J.H.; Hwang, N.S.; Heo, C.Y. Bioactive calcium phosphate materials and applications in bone regeneration. Biomater Res. 2019, 23, https://doi.org/10.1186/s40824-018-0149-3.

15. Zhu, Y.W.; Wen, J.; Jiang, X.X.; Wang, W.C.; Yang. L. High calcium to phosphorus ratio impairs growth and bone mineralization in Pekin ducklings. Poultry Science 2018, 97, 1163-1169, https://doi.org/10.3382/ps/pex401.

16. Oliveira Matheus, J.C.; Bonan, R.F.; Campos, S.G.; Neves, G.; Menezes, R.R. Calcium phosphate submicrometric fibers produced by solution blow spinning. Materials Research 2019, 22, https://doi.org/10.1590/1980-5373-mr-2018-0753.

17. Nascimento, MQ, Vargas Junior, JG, Pinto, CEL, Demuner, LF, Petrucci, FB, \& Vieites, FM. Optimal Available Phosphorus Levels in Diets Containing Different Dicalcium Phosphate Particle Sizes for Japanese Quails. Brazilian Journal of Poultry Science 2019, 21, https://doi.org/10.1590/1806-9061-2018-0878.

18. Corrêa, T.H.A.; Holanda, J.N.F. Fish Bone as a Source of Raw Material for Synthesis of Calcium Phosphate. Materials Research 2019, 22, https://dx.doi.org/10.1590/1980-5373-mr-2019-0486. b 
19. Zhao, J.; Liu, Y.; Sun, W.; Yang, X. First detection, characterization, and application of amorphous calcium phosphate in dentistry. Journal of Dental Sciences 2012, 7, 316-323, http://dx.doi.org/10.1016/j.jds.2012.09.001.

20. Guastaldi, A.C.; Herrera Aparecida, A. Fosfatos de cálcio de interesse biológico: Importância como biomateriais, propriedades e métodos de obtenção de recobrimentos. Quim. Nova 2010, 33, 1352-1358, http://dx.doi.org/10.1590/S0100-40422010000600025.

21. House, W.A. The physico chemical conditions for the precipitation of phosphate with calcium. Environmental Technology 1999, 20, 727-733, https://doi.org/10.1080/09593332008616867.

22. Lin, F.; Liao, C.J.; Chen, K.S.; Sun, J.S.; Lin, C.P. Petal-like apatite formed on the surface of tricalcium phosphate ceramic after soaking in distilled water. Biomaterials 2001, 22, 2981-2992, https://doi.org/10.1016/s0142-9612(01)00044-8.

23. Londoño, M.E.; Echavarría, A.; Calle, F. Características cristaloquímicas de la hidroxiapatita sintética tratada a diferentes temperaturas. Revista EIA 2006, 5, 109-118. 